\title{
Parkinson's syndrome after closed head injury: a single case report
}

\author{
M Doder, M Jahanshahi, N Turjanski, I F Moseley, A J Lees
}

The National Hospital for Neurology and Neurosurgery, Queen Square, London, UK $M$ Doder I F Moseley

A J Lees

Department of Clinical Neurology, Institute of Neurology, Medical Research Council, Human Movements and Balance Unit, Queen square, London, UK

M Jahanshahi

MRC Cyclotron Unit, Hamersmith Hospital, Ducane Road, London, UK

N Turjanski

Correspondence to: Dr AJ Lees, The National Hospital for Neurology and Neurosurgery, Queen Square, London WC1N 3BG, UK.

Received 12 March 1998 and in revised form 29 June 1998

Accepted 9 July 1998

\begin{abstract}
A 36 year old man, who sustained a skull fracture in 1984, was unconscious for 24 hours, and developed signs of Parkinson's syndrome 6 weeks after the injury. When assessed in 1995, neuroimaging disclosed a cerebral infarction due to trauma involving the left caudate and lenticular nucleus. Parkinson's syndrome was predominantly right sided, slowly progressive, and unresponsive to levodopa therapy. Reaction time tests showed slowness of movement initiation and execution with both hands, particularly the right. Recording of movement related cortical potentials suggested bilateral deficits in movement preparation. Neuropsychological assessment disclosed no evidence of major deficits on tests assessing executive function or working memory, with the exception of selective impairments on the Stroop and on a test of self ordered random number sequences. There was evidence of abulia. The results are discussed in relation to previous literature on basal ganglia lesions and the effects of damage to different points of the frontostriatal circuits.

(F Neurol Neurosurg Psychiatry 1999;66:380-385)
\end{abstract}

Keywords: parkinsonism; closed head injury; case report

Parkinson's syndrome as a component of posttraumatic encephalopathy in boxers and $\mathrm{Na}$ tional Hunt steeple chase jockeys is well recognised. ${ }^{1}$ A relatively pure "striatal" variant of the punch drunk syndrome has also been occasionally described. ${ }^{2}$ However, very few convincing cases have been described after a single closed head injury. More than 50 years ago, Crouzon and Justin-Besancon ${ }^{3}$ proposed a set of minimum operational criteria for the diagnosis of Parkinson's syndrome secondary to acute head injury. They considered that the trauma should be severe and have led to concussion or unconsciousness, that there should be a close temporal relation between the acute trauma and the onset of parkinsonian features, and that the course of the subsequent Parkinson's syndrome should be uninterrupted. Factor et al increased the stringency of these criteria by insisting that there should also be evidence of midbrain damage or compression established at necropsy or by neuroimaging. ${ }^{4}$

The only convincing examples of posttraumatic parkinsonism after acute closed head trauma that we have found in the literature are the cases reported by Lindenberg ${ }^{5}$ and the report by Nayernouri. ${ }^{6}$ The first case of parkinsonism after an acute spontaneous intracranial haematoma, after rupture of a right middle cerebral artery aneurism, has recently been described. ${ }^{7}$ Well documented cases of parkinsonism after a contralateral ischaemic lesion of the striatum are rare. Fenelon and Houeto reported a case of non-progressive unilateral parkinsonism occurring a few months after an ischaemic stroke. ${ }^{8}$ Brain MRI was suggestive of an ischaemic lesion in the territory of the left lenticulostriate arteries involving the entire striatum, apart from the fundus striati, and probably most of the lateral pallidum.

We now report a further case of Parkinson's syndrome, which we consider to have occurred probably as a direct consequence of closed head trauma.

\section{Case report}

A 24 year old barman was involved in a road traffic accident in 1984 . He sustained a skull fracture and a fractured right arm, and was unconscious for 24 hours with post-traumatic amnesia lasting several weeks. According to the patient and accessible medical notes he was in hospital for 1 month, during which time he received no neuroleptic drugs. Six weeks after the head injury, the patient noticed a coarse resting tremor, marked loss of dexterity, and slowness in his right hand, and complained of forgetfulness. Over the next 3 years there was little change in his symptoms, but in 1989 he started to drag his right foot and noticed a mild additional shaking of his right leg. Seven years after the accident, a mild resting tremor of his left hand appeared and his speech was increasingly slurred. Over the next few years a slow progression of his parkinsonism occurred, with no response to levodopa or anticholinergic therapy.

In June 1995, he was seen at the National Hospital for Neurology and Neurosurgery. There was no history of previous exposure to dopamine antagonists. He smoked 10 cigarettes 

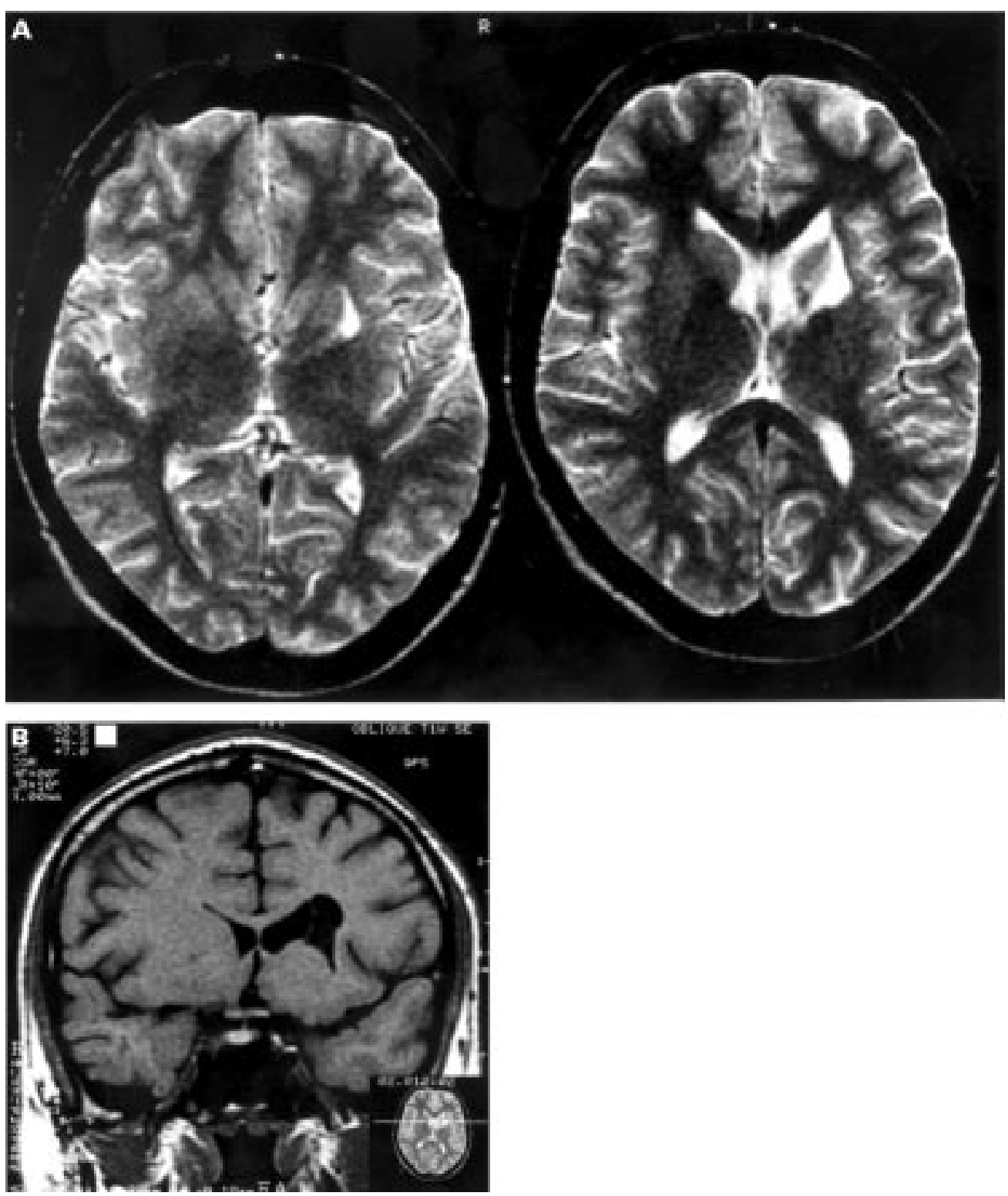

Figure 1 ( $A$ and $B)$ MRI showing a well defined area of abnormal signal adjacent to the frontal horn and anterior part of the body of a slightly enlarged left lateral ventricle, most probably a post-traumatic infarct.

a day and had drunk 30 units of alcohol a week for the past 10 years. He was developmentally dyslexic, and had attended a special school up to the age of 15 , after which he had worked as a steeplejack and later as a storeman and then as a barman. He had been right handed before the accident, but had subsequently switched to using his left hand for many dexterous activities. There was no family history of Parkinson's syndrome or essential tremor.

On examination, he had an oblique scar in the medial region of his forehead about $9 \mathrm{~cm}$ long. He was alert and oriented, but was slow to respond to questions. $\mathrm{He}$ had facial hypomimia, a markedly reduced blink rate with a positive glabellar tap sign and occasional blepharoclonus. Eye movements were full in range, but he had diminished convergence and fine horizontal gaze evoked nystagmus to the left. His tongue was tremulous and his speech quiet and monotonous. There was a coarse pill rolling, 5 cycles/second, resting tremor of the right hand with an associated postural tremor, and a mild resting tremor of his right leg and left hand. He had severe right sided lead pipe rigidity with cogwheeling at the right wrist and mild left sided stiffness. There was moderate bilateral bradykinesia and hypokinesia, worse on the right than the left, with striking micrographia. He had absent right arm swing and a slightly diminished left arm swing.

The fractured right arm was well healed by the time of our assessment and there was no residual loss of function.

There were no cerebellar signs, the plantar responses were downgoing, and there was no evidence of autonomic failure.

Normal investigations included a full blood count, urea and electrolytes, fasting blood glucose, lipids, serum $\mathrm{B}_{12}$, thyroid function, routine liver function tests, serum copper, and caeruloplasmin. Wet blood film screening for acanthocytes was negative and treponemal serological tests were also negative. His eryth- 


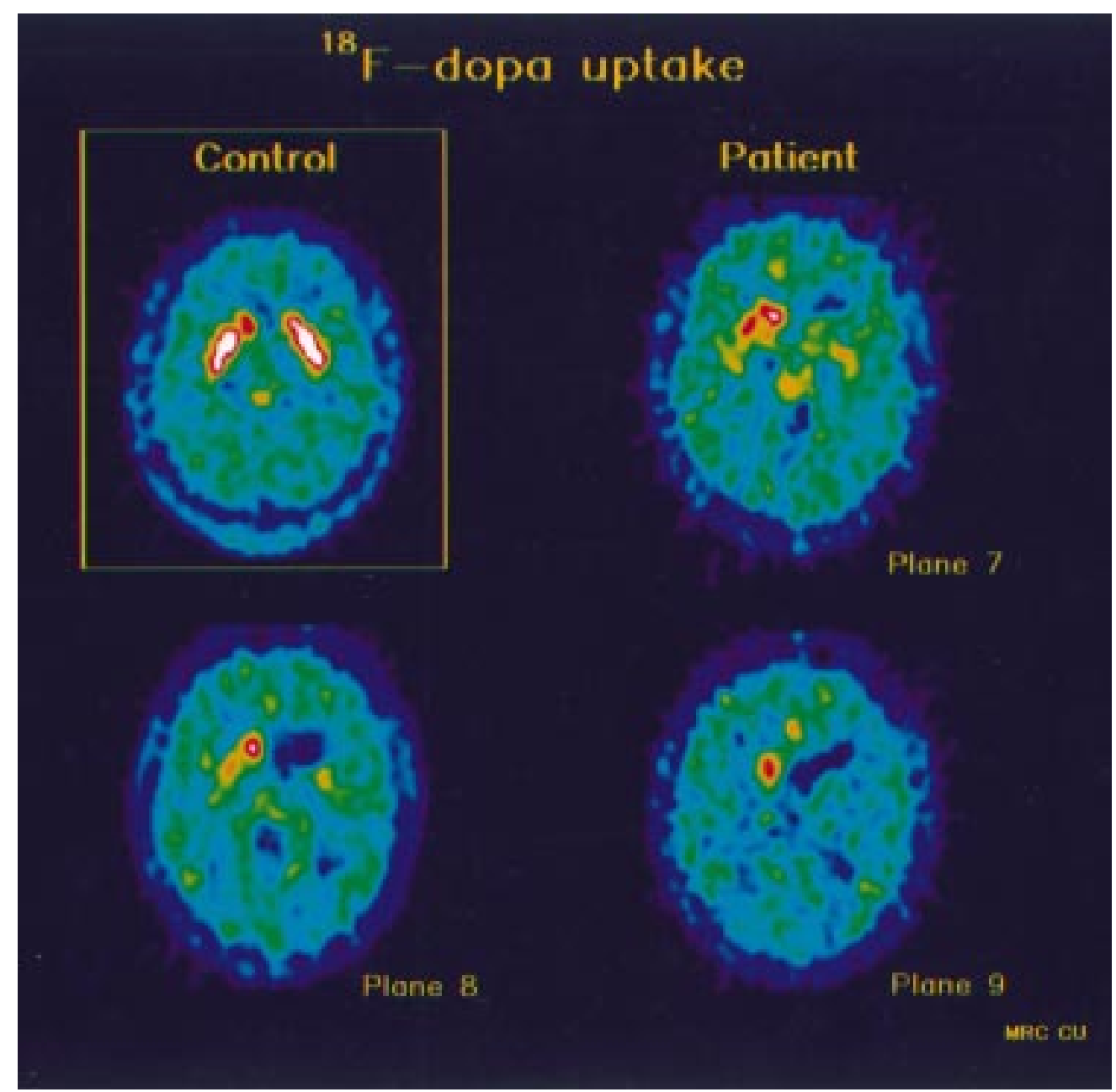

Figure 2 Positron emision tomography using ${ }^{18} \mathrm{~F}$-dopa showing bilateral reduction of putamen uptake.

rocyte sedimentation rate was $12 \mathrm{ml} /$ hour and chest radiography, ECG, and EEG were normal. Slit lamp examination showed no Kayser-Fleischer rings.

Finally, an acute subcutaneous apomorphine challenge and oral levodopa challenge tests were negative, confirming dopaminergic unresponsiveness. However, he developed choreiform peak dose diskinesia in his right arm on increasing the dose of sinemet to $1000 \mathrm{mg}$ daily in January 1998.

\section{Results}

NEUROIMAGING

Brain CT showed an area of low density, interpreted as focal brain damage, in the left caudate nucleus, extending into the lentiform nucleus, with ex vacuo enlargement of the adjacent frontal horn.

On brain MRI this area was seen as a well defined area of non-specifically altered signal, slightly higher than that of CSF on all sequences; it was concluded that this was most probably a post-traumatic infarct. The lesion involved the head and the anterior part of the body of the caudate nucleus, extending laterally into the anterior limb of the internal capsule, reaching as far as the genu, and across to the anterior third of the putamen. It extended superolaterally into the centrum semiovale and inferiorly to the anterior part of the globus pallidus. There was in addition a small focus of similarly non-specific abnormal signal in the white matter of the anterior right temporal lobe, associated with minor shrinkage, presumed to represent postcontusional encephalomalacia. The remainder of the cerebral hemispheres seemed normal, as did the midbrain and infratentorial structures (fig $1 \mathrm{~A}$ and $\mathrm{B}$ ).

A brain perfusion SPECT study showed a single abnormality seen as an area of focal reduction in perfusion to the white matter close to the left basal ganglia. The perfusion ratios to the grey matter of the cortex and to the basal ganglia on the right hemisphere were within normal limits.

Positron emission tomography using ${ }^{18} \mathrm{~F}$ dopa showed a reduced uptake in the right putamen $\left(0.0055 \mathrm{Ki} \mathrm{min}^{-1}\right)$ and normal caudate $\left(0.0091 \mathrm{Ki} \mathrm{min}^{-1}\right)$ compared with control values (caudate $0.0106+0.0019$, putamen $\left.0.0098+0.0011 \mathrm{Ki} \mathrm{min}^{-1}\right)$. The ${ }^{18} \mathrm{~F}$-dopa uptake on the left side was also markedly reduced, however, the anatomical distortion, induced by the lesion made this result uninterpretable (fig 2).

\section{NEUROPSYCHOLOGICAL ASSESSMENT}

Our patient had undergone neuropsychological assessment on two previous occasions: the 
first in 1994, 10 years after the head injury, and the second 9 months after the first. The current assessment was performed 3 months after this second assessment and included neuropsychological tests, of which we summarise only the most relevant results.

The Wechsler adult intelligence scale-revised ${ }^{9}$ indicated functioning at a low average to borderline level, reflecting a pattern of ability which was longstanding and developmental in origin. Reading and spelling tests ${ }^{10}$ reflected dyslexic difficulties.

During the current assessment of memory functions, on the Rey auditory verbal learning tes $\mathrm{t}^{11}$ his immediate span was low for his age, but probably in accord with his intellectual level. He showed some evidence of verbal learning, but also some loss of material after a delay of 45 minutes, with three false positives.

Performance was also assessed on some tests of executive function, such as the Wisconsin card sorting test, Weigl sorting task, verbal fluency, Reitan trail making, and Stroop test. ${ }^{12-16}$ With the exception of the Stroop colour word test $^{16}$ there was little evidence of deficits on tests of executive function or behavioural regulation. On the Stroop test, interference was evident during colour naming of 32 colour words written in incongruent ink compared with naming the colour of 32 coloured rectangles.

We also evaluated our patient's performance on tests of working memory which require holding information "on line" and monitoring responses. He showed a selective impairment on the test of self ordered random number sequence ${ }^{17}$ and similar to that for patients with Parkinson's disease. ${ }^{18}$

On the Beck depression inventory (BDI) he obtained a score of $26 .{ }^{19}$

ASSESSMENT OF MOVEMENT PREPARATION, INITIATION, AND EXECUTION

Visual simple (SRT) and four choice (CRT) reaction time tasks were completed, as well as the Purdue pegboard and index finger tapping. ${ }^{18} 20$ On all these tests our patient performed worse than an age matched healthy normal subject and similar to previously published data ${ }^{18}{ }^{20}$ for elderly patients with Parkinson's disease. For both the SRT and CRT tasks his initiation times were slightly slower and his movement times considerably slower with the right hand compared with the left. Movement related cortical potentials (MRCPs) in our patient were compared with a normal age matched subject, and the amplitude of all components was reduced. ${ }^{21}$ The MRCPs before left hand movements had a smaller amplitude and more delayed onset, with the early Bereitschaft Potential component possibly being absent, suggesting bilateral deficits in MRCPs.

\section{Discussion}

The association between acute head injury and the development of a Parkinson's syndrome has been an issue of controversial debate since James Parkinson's essay in $1817 .^{22}$ Although authors reported Parkinson's syndrome after craniocerebral trauma, ${ }^{23-29}$ there have been only a few cases with sufficient evidence to implicate closed head trauma as an aetiological factor. It is possible that the rarity of reported cases reflects the fact that head injuries severe enough to badly damage the basal ganglia often lead to death. ${ }^{29}{ }^{30}$ Mechanisms which may be relevant to the development of Parkinson's syndrome after acute head injury include tearing of small brain stem vessels by shearing forces, direct traumatic injury to blood vessels leading to secondary thrombosis and infarction, and downward displacement of the brain stem leading to contusion or haemorrhage. Tears occurring between the substantia nigra and surrounding structures and the cerebral peduncle may also be important pathogenetic factors. It is also possible that morphological changes may not indicate the full extent of traumatic damage, but changes in neurotransmitter sensitivity and distal functional effects may also be important.

We think that acute head trauma is the likeliest aetiological cause for the Parkinson's syndrome in our patient. There was a close temporal relation between the onset of symptoms and the head injury which was severe enough to leave radiologically demonstrable focal brain injury in the left lenticular nucleus. The Parkinson's syndrome progressed much more slowly than expected for either Parkinson's disease or another neurodegenerative cause such as multiple system atrophy and there was no response to dopaminergic therapy. Functional imaging indicated that there was bilateral impairment of dopamine function in the nigrostriatal terminals, raising the possibility that the head injury had caused more substantial damage than was evident on anatomical imaging. Bilateral reduction in tracer uptake also raises the possibility that our patient's symptoms might be consistent with idiopathic Parkinson's disease, or that unilateral structural damage (left caudate and lenticular nucleus in our patient) can cause bilateral striatal dopaminergic dysfunction with retrograde degeneration of nigrostriatal terminals. Unilateral dopamine denervation models support the potential importance of dopaminergic interdependence between the two nigrostriatal systems. ${ }^{31-35}$ For example, bilateral striatal dopamine depletion induced by unilateral lesion dorsal to substantia nigra was described in monkeys. ${ }^{35}$ The nigral dopamine was severely reduced on both sides in the chronic experiments weeks after a unilateral caudate lesion in cats. ${ }^{34}$

From a meta-analysis of the 240 cases with focal basal ganglia lesions reported in the literature, Bhatia and Marsden ${ }^{36}$ concluded that Parkinson's syndrome was exeptionally rare, found only in 16 of the 240 cases $(6 \%)$. Small $(n=1)$ or large $(n=4)$ lesions of the putamen, small $(n=4)$ or large $(n=1)$ lesion of the globus pallidus, or the lentiform nucleus $(n=3)$, and in one case a large caudate lesion. In the patient studied by us, such a predominantly left sided subcortical damage was associated with a mainly right sided parkinsonism. There was also slowness of initiation of movement and particularly movement execution quanti- 
fied on the reaction time tasks, and alterations of MRCPs. Such deficits have previously been reported for elderly patients with Parkinson's disease. ${ }^{18-21}$

There is evidence of an asymmetry of motor effects after cortical lesions. Wyke ${ }^{37}$ reported that whereas dominant hemispheric lesions produced bilateral motor deficits, damage to the non-dominant hemisphere affected only contralateral limb movement. In our patient, the bilateral nature of the deficits shown by the reaction time tasks and MRCPs raises the possibility that subcortical motor structures show a hemispheric asymmetry-similar to that found after cortical damage.

Abulia - that is, apathy with loss of initiative, spontaneous thought, and emotional responses-was found to be the commonest behavioural disturbance among 240 cases with focal lesions of the basal ganglia. ${ }^{38}$

In light of this, our patient's slowness in responding to questions during the interview and the high score on BDI are of interest. $\mathrm{He}$ had endorsed items reflecting loss of interest, lack of enjoyment, difficulty in decision making, greater sense of fatigue, but absence of sadness. These suggest abulia rather than depression. Abulia is primarily a motivational deficit that can impair performance of willed actions. The surface manifestations of abulia can be similar to bradykinesia and akinesia, which are motoric deficits. Therefore, it is possible that the slowness of movement initiation and execution found in our patient by the reaction time tests, partly reflects the motivational deficits associated with abulia rather than the motor slowness associated with bradykinesia.

The current assessment suggested some loss of learnt material after a delay of 45 minutes. However, as impaired delayed recall was combined with correct delayed recognition of the 15 words, albeit with three false positives, this suggests mainly retrieval rather than retention deficits. The cause of the memory problems are difficult to determine. Focal lesions of the basal ganglia can be associated with retrieval deficits, ${ }^{39}$ and presence of abulia can contribute to impairment of effortful retrieval. Additionally, in our patient MRI showed an abnormal signal in the anterior right temporal cortex, and on that basis impairment on tests of non-verbal memory would be expected. Memory for nonverbal material was not included in the current assessment and the results of the two prior assessments of cognitive function were inconsistent with regard to the presence or absence of such memory deficits.

Focal lesions of the basal ganglia do not result in uniform effects on cognitive function. Dubois $e t a l^{\beta 8}$ concluded that in terms of cognitive function, lesions of basal ganglia are associated with normal intellectual efficiency, preserved linguistic and spatial abilities, limited "frontal" dysfunction, memory retrieval deficit, and procedural learning disorders. They noted that the dysexecutive syndrome seen in patients with basal ganglia lesions was less severe than in patients with degenerative diseases of the basal ganglia such as Parkinson's disease.
This finding is borne out by the case studied by us. This patient was assessed on a range of tests considered to tap "frontal" executive function. With the exception of the Stroop test, there was little evidence of deficits on tests on which patients with idiopathic Parkinson's disease have been found to be significantly impaired. $^{20}$ Successful performance on the Stroop test requires development of a "perceptual set" for suppression of the dominant response of reading the words to name the colour of ink of the colour words printed in colour incongruent ink. Our patient had problems in developing or maintaining such a set. This was coupled with a selective impairment on a specific test of working memory, self ordered random number sequences, with relatively normal performance on other tests of working memory, such as self ordered pointing, random number generation, and missing digits. This selective impairment on a specific test of working memory is reminiscent of the results reported by Robbins et al, ${ }^{39}$ who studied a young man with a left striatocapsular infarct, with a specific deficit when "carrying out a form of working memory task in which the subject has to 'self-order' a series of responses using a self-generated strategy". These same processes are also involved in the self ordered random number sequences on which our patient was impaired.

In monkeys, lesions of the dorsolateral prefrontal cortex have been shown to impair performance on tasks involving non-spatial working memory requiring monitoring and self ordered performance. ${ }^{40}$ The test of self ordered random number sequences used in the current study has previously been shown to activate the dorsolateral prefrontal cortex in a PET study with healthy participants. ${ }^{41}$

The finding that our patient with damage predominantly to the left striatum showed a selective impairment on this test, suggests that as the effects of damage to the prefrontal cortex in the monkey, ${ }^{42}$ damage to the striatum can also produce deficits in self ordered working memory.

This is consistent with previous evidence that in the monkey, similar deficits are produced on tasks such as the delayed response or object reversal after lesioning the prefrontal cortex or the striatum - that is, at two different points in the frontostriatal loops. ${ }^{42}{ }^{43}$ However, our patient and the case studied by Robbins et $a l,{ }^{39}$ showed a specific impairment of working memory in the absence of major deficits in other tests of executive function previously found to be impaired in patients with damage to the frontal cortex. ${ }^{44}$ This suggests that despite similarities, in humans, the effects of striatal and prefrontal lesions are not quantitatively or qualitatively identical. ${ }^{40} 44$

The financial assistance of the Welcome Trust (MJ) is gratefully acknowledged. We thank Dr Patricia Limousin for providing the recording of MRCPs in a normal subject and Dr D Costa from Department of Nuclear Medicine at Middlesex Hospital for carrying out the SPECT.

1 Foster JB, Leiguarda R, Tilley PJ. Brain damage in National Hunt jockeys. Lancet 1976;1:981-2. 
2 Critchley M. Medical aspects of boxing, particularly from a neurological point of view. BMF 1957; ; :357-66.

Crouson O Justin-Besancon I Le Parkinsonism traumatique. Presse Med 1929;37:1325-7.

4 Factor SA, Sanchez-Ramos J, Weiner JW. Trauma as an etiology of parkinsonism: a historical review of the concept. Mov Disord 1988;3:30-6.

5 Lindenberg R. Die Schadigunsmechanismes der substantia nigra beihirntraumen und das problem des posttraumatischen Parkinsonismus. Deutsche Zeitschrift Für Nervenheilkunde 1964;185:637-63.

6 Nayernouri T. Posttraumatic parkinsonism. Surg Neurol 1985;24:263-4.

7 Turjanski N, Pentland B, Lees AJ, et al. Parkinsonism associated with acute intracranial hematomas: an $[18 \mathrm{~F}]$ dopa positron emission tomography study. Mov Disord 1997;12: positron 8 .

8 Fenelon G, Houeto JL. Unilateral parkinsonism following a large infarct in the territory of the lenticulostriate arteries. Mov Disord 1997;12:1086-90.

9 Wechsler D. Adult intelligence scale-revised (WAIS-R). Harcourt Brace: Psychological Corporation.

10 Schonell F. Backwardness in basic subjects. London: Oliver and Boyd, 1942 .

11 Rey A. L'examen clinique en psychologie. Paris: Presses Universitaires de France, 1964

12 Nelson HE. A modified card sorting test sensitive to frontal lobe defects. Cortex 1976;12:313-24.

13 Weigl E. On the psychology of so-called processes of abstraction. Fournal of Abnormal Social Psychology 1941;36 3-33.

14 Benton AL, Hamsher K. Multilingual aphasia examination. Iowa City. University of Iowa, 1976, manual revised, 1978.

15 Reitan RM. Validity of the trail making test as an indicator of organic brain damage. Percept Mot Skills 1958;8:271-6.

16 Stroop JR. Studies of interference in serial verbal reactions. Fournal of Experimental Psychology 1935;18:643-662.

17 Petrides M, Alivisastos B, Meyer R, et al. Functional activation of the human frontal cortex during the performance of verbal working memory tasks. Proc Natl Acad Sci 1993;90: 878-82.

18 Brown RG, Jahanshahi M, Marsden CD. The execution of bimanual movements in patients with neurological disease. f Neurol Neurosurg Psychiatry 1993;56:295-7.

19 Beck AT, Ward CH, Mendelson M, et al. An inventory for measuring depression. Arch Gen Psychiatry 1961;4:651-71

20 Jahanshahi M, Brown RG, Marsden CD. Simple and choice reaction time and the use of advance information for moto preparation in Parkinson's disease. Brain 1992;115:539654.

21 Touge T, Werhan KJ, Rothwell JC, et al. Movement -related cortical potentials preceding repetitive and random-choice hand movements in Parkinson's disease. Ann Neurol 1995; 37:791-9.

22 Parkinson J. Essay on the shaking palsy. London: Whittingham and Rowland, for Sherwood, Neely, and Jones, 1817

23 Jentzer A, De Morsier G. Hemiparkinsonism droit postraumatique avec lesion du noyau rouge et du locus niger. $\mathrm{Sch}$ matique avec lesion du noyau rouge et durch Neurol Psychiatr 1947;60:388.

24 De Morsier G. Parkinsonism consecutif a une lesion traumatique du noyau rouge et du locus niger. Psychiatria et Neurologia 1960;139:60-84.
25 Grimberg L. Paralysis agitans and trauma. F Nerv Ment Dis 1934;79:711-20.

26 Pratar Chand R. Posttraumatic parkinsonian syndrome: a case report. Med $\mathcal{F}$ Malaysia 1985;40:335-7.

27 Takeda M, Okuda B, Tomino J, et al. A case of posttraumatic parkinsonism. Rinsho Shinkeigaku 1991;31:842-6.

28 Della Sala S, Mazzini L. Post-traumatic extrapyramidal syndrome: case report. Ital F Neurol Sci 1993;11:65-9.

29 Factor SA, Sanchez-Ramos J, Weiner JW, et al. Trauma as an etiology of parkinsonism: opinions in the nineteenth century. Mov Disord 1989;4:283-5.

30 Rosenblum WI, Greenberg KP, Seelig JH, et al. Midbrain lesions: frequent and significant prognostic feature in closed head injury. Neurosurgery 1981;9:613-20.

31 Chandu-Lall JA, Haase GR, Zivanovic D, et al. Dopamine interdependence between the caudate nuclei. Exp Neurol 1970;29:101-10

32 Sourkes TL, Poirier LJ. Influence of substantia nigra on concentration of 5-hydroxytryptamine and dopamine of the striatum. Nature 1966;207:202-3.

33 Altar A, Neve KA, Lough, et al. The crossed mesostriatal projection: neurochemistry and developmental response to lession. Brain Res 1983;279:1-8.

34 Cheramy A, Leviel V, Daudet F, et al. Involvement of the thalamus on the reciprocal regulation of the two nigrostriatal dopaminergic pathways. Neuroscience 1981;6:2657-68.

35 Lawler CP, Gilmore JH, Watts VJ, et al. Interhemispheric modulation of dopamine receptor interactions in unilateral 6-OHDA rodent model. Synapse 1995;21:299-311.

36 Bhatia KP, Marsden CD. The behavioral and motor consequences of focal lesions of the basal ganglia in man. Brain 1994;117:859-76.

37 Wyke $M$. Effect of brain lesions on the rapidity of arm movement. Neurology 1967;17:1113-20.

38 Dubois B, Defontaines B, Deweer B, et al. Cognitive and behavioral changes in patients with focal lesions of the basal ganglia. In: WJ Weiner, AE Lang, eds. Behavioral neurology of movement disorders. Vol 65. New York: Raven Press, 1995: 29-41.

39 Robbins TW, Shallice T, Burgess PW, et al. Selective impairments in self-ordered working memory in a patient with a unilateral striatal lesion. Neuroscience 1995;1:217-30.

40 Petrides M. Impairment on non-spatial, self-ordered, and externally oriented memory tasks after lesions of the mid-dorsal part of the lateral prefrontal cortex of the monkey. F Neurosci 1995;15:359-75.

41 Battig K, Rosvold HE, Mishkin M. Comparison of the effects of frontal and caudate lesions on delayed response and alternation in monkeys. F Comp Physiol Psychol 1991;13:909-22.

42 Divac I, Rosvold HE, Szwarcbart MR. Behavioral effects of selective ablation of the caudate nucleus. Fournal of Comparative Physiology and Psychology 1967;63:184-90.

43 Milner B. Some effects of frontal lobectomy in man. In: JM Warren, $\mathrm{K}$ Akert, eds. The frontal agranular cortex and behavior. New York: McGraw-Hill, 1964.

44 Owen AM, Roberts AC Hodges JR, et al. Contrasting mechanisms of impaired attentional set-shifting in patients 1993;116:1159-79. 